\title{
Effect of Nitrogen Level on Growth and Metabolism of Allium fistulosum
} L.

\author{
Lin Zhou ${ }^{1 \S, a}$, Qiulin Yue ${ }^{1 \S, b}$, Lin Zhao ${ }^{1 *, c}$, Rongzong Cuil,d, Xinli Liü,e
}

1 Shandong Provincial Key Lab. of Microbial Engineering, Qi Lu University of Technology (Shandong Academy of Sciences), Jinan 250353, P.R. China
2 Institute of Agricultural Resources and Environment, Shandong Academy of Agricultural Sciences, Jinan 250100, P.R. China
aqinlin_jinan@163.com, byueqiulin88@163.com, 'sdilizhaolin@163.com, drzcui@ipni.ac.cn,
evip.|x|@163.com

$\S$ These authors contributed equally to this work.

* Correspondence: sdilizhaolin@163.com; Tel \& fax: +86 53189631776

\begin{abstract}
Keywords: Allium fistulosum L; nitrogen metabolism; enzymes; quality
Abstract. The effect of nitrogen on growth and nitrogen metabolism of Allium fistulosum L. was investigated to clarify the role of $\mathrm{N}$ in affecting the quality, and provide a theoretical basis for the optimization fertilization technique. Three nitrogen levels were tested in the experiment, namely total nitrogen, half nitrogen and free nitrogen. By measuring the activities of enzymes related to nitrogen metabolism in Allium fistulosum L. at four growth stages, the results showed that nitrate reductase (NR), glutamate synthetase (GOGAT) and glutamate dehydrogenase (GDH) had the highest activity in vigorous growth stage with half nitrogen supply. The activity of Glutamine synthetase (GS) was the highest in the vigorous growth stage. With the increase of nitrogen level, The contents of soluble sugar, vitamin $\mathrm{C}$ increased first and then decreased. The contents of nitrate, pyruvic acid and free amino acids showed an increasing trend with the increasing of nitrogen level.
\end{abstract}

\section{Introduction}

Allium fistulosum $\mathrm{L}$ is a perennial herb. Its fertility stage is generally divided into seedling over-summer stage, vigorous growth stage, cauloid forming stage and Harvest stage $\mathrm{e}^{[1]}$. China is the main country of scallion cultivation. The main species in the north is "Great Indus", which is characterized by a bitter spicy flavor, light and light sweetness, crisp and delicious, large green onion and long lasting storage ${ }^{[2]}$. Nitrogen is a large number of elements necessary for plant growth and is an important element in the formation of proteins, phospholipids, nucleic acids and organic nitrides. Protein, nucleic acid and lipid are the most basic substances that form cytoplasm,nucleus and biofilm $^{[3]}$. Therefore, nitrogen is called life element. Nitrogen has a significant influence on the quality of scallion.

Stems and leaves are rich in amino acids, protein, vitamin $\mathrm{C}$ and other nutrients. The final production of nitrogen is amino acids and proteins which are positively correlated with the quality of Allium fistulosum $\mathrm{L}^{[4]}$. Nitrogen is one of the most important nutrients during the growth and development of it. The metabolism of nitrogen is a very important physiological process in the plants. The assimilation of nitrogen is mainly catalyzed by key enzymes such as nitrate reductase, glutamine synthetase, glutamate synthase and glutamate dehydrogenase and so on. It is of great significance to study the mechanism of nitrogen metabolism in terms of creating scallion quality by exploring the effect of nitrogen application rate on the key enzyme activities of nitrogen metabolism and nutrients in different growth stages which has very important theoretical and practical significance for the rational use of nitrogen fertilizer ${ }^{[5]}$. The research provides a theoretical basis of improving the efficiency of nitrogen fertilizer . 


\section{Materials and methods}

Materials. The test was carried out in the experimental dwarf area of Zhangqiu, Jinan in , for three different conditions including nitrogen-free level, total nitrogen level and nitrogen level halved, each of which was processed in three parallel. In accordance with the nutrient requirements in the bearing stage of scallion. Nitrogen fertilizer was divided into 3-4 times. The samples of Allium fistulosum L were collected for testing in the summer period (July 17th), Fast growing leaves period (September 11 th), pseudo stem enrichment period (October 20th) and Harvest (November 13th $)^{[1]}$.

Enzyme activity of nitrogen metabolism determination. Nitrate reductase (NR) activity assay ${ }^{[6]}$. $0.5 \mathrm{~g}$ leaves of Scallion were shredded and put into test tubes. Adding $1 \mathrm{ml} 30 \%$ TCA (trichloroacetic acid) to the control group, each tube added $9 \mathrm{~mL}, 0.2 \mathrm{moL} / \mathrm{L} \mathrm{KNO}_{3}$ solution. Then each tube pumped vacuum $1 \mathrm{~h}$ and placed in dark for $30 \mathrm{~min}$ at $25{ }^{\circ} \mathrm{C}$. Then $1 \mathrm{~mL} 30 \%$ TCA was added to each test tube to stop the reaction except the control group. Putting $1 \mathrm{~mL}$ supernatant into a new tube then added $1 \%$ sulfonamide solution and $0.2 \%$ naphthylamine solution, colouring for $20 \mathrm{mins}$, and finally measured the absorbance at $540 \mathrm{~nm}$.

Glutamine synthetase (GS) activity assay ${ }^{[7]} .1 .0 \mathrm{~g}$ green leaves were mixed with $3 \mathrm{ml}$ solution (50 $\mathrm{mmoL} / \mathrm{L} \mathrm{ph}=8$ Tris-HCl, $2 \mathrm{mmoL} / \mathrm{L} \mathrm{Mg}^{2+}, 2 \mathrm{mmoL} / \mathrm{L}$ DTT, $0.4 \mathrm{~mol} / 1$ sucrose), Frozen grinding, sucked into a $2 \mathrm{~mL}$ centrifuge tube. It is centrifuged by $12000 \mathrm{r} / \mathrm{min}$ for $20 \mathrm{mins}$ (supernatant is the crude enzyme solution). $0.7 \mathrm{~mL}$ supernatant were added to a new tube was mixed with $1.6 \mathrm{~mL}$ reaction solution A $\left(100 \mathrm{mmoL} / \mathrm{L} \mathrm{pH}=7.4 \mathrm{Tris}-\mathrm{HCl}, 80 \mathrm{mmoL} / \mathrm{L} \mathrm{Mg}^{2+}, 20 \mathrm{mmoL} / \mathrm{L}\right.$ sodium glutamate, And $20 \mathrm{mmoL} / \mathrm{L}$ cysteine) and reaction solutionB(reaction solutionA, $80 \mathrm{mmol} / 1$ hydroxylamine hydrochloride). Then the thermostatic water bath was carried out at $37^{\circ} \mathrm{C}$ for 30 mins. After that, added $1.0 \mathrm{~mL}$ color reagent $\left(0.2 \mathrm{moL} / \mathrm{L}\right.$ TCA, $0.37 \mathrm{moL} / \mathrm{L} \mathrm{FeCl}{ }_{3}$ and $0.6 \mathrm{moL} / \mathrm{L}$ $\mathrm{HCl}$ ) with sufficient mixing. Centrifuging at $5000 \mathrm{r} / \mathrm{min}$ for $10 \mathrm{mins}$. The reaction liquid A was taked as blank control. The absorbance of supernatant was measured at $540 \mathrm{~nm}$. Another $0.05 \mathrm{~mL}$ crude enzyme solution was used to measure the content of soluble protein by coomassie brilliant blue.

Glutamate dehydrogenase (GDH) activity assay ${ }^{[1]} .0 .5 \mathrm{ml}$ crude enzyme solution was uniformly mixed with $2.5 \mathrm{ml}$ of reaction solution $(0.3 \mathrm{~mL}$ of $0.1 \mathrm{M} \alpha$-Ketoglutaric acid, $0.3 \mathrm{ml}$ of $1 \mathrm{M} \mathrm{NH}_{4} \mathrm{Cl}, 0.2 \mathrm{ml}$ of $3 \mathrm{mM}$ NADH-Na, $1.7 \mathrm{~mL}$ of $0.2 \mathrm{M}$ Tris-HCl pH8.0). Immediately, the mixture measured kinetic curve with an interval of $48 \mathrm{~s}$, a total of 8 mins at $340 \mathrm{~nm}$. Consider the reaction solution reducing $1 \mu \mathrm{mol} \mathrm{NADH}-\mathrm{Na} 2$ variation per minute as an enzyme unit ${ }^{[12]}$.

Glutamate synthase (GOGAT) assay. $0.2 \mathrm{~mL}$ crude enzyme solution was uniformly mixed with $2.8 \mathrm{~mL}$ of reaction mixture $(0.4 \mathrm{~mL}$ of $20 \mathrm{mM}$ L-glutamic acid, $0.05 \mathrm{~mL}$ of $0.1 \mathrm{M} \alpha$-Ketoglutaric acid,

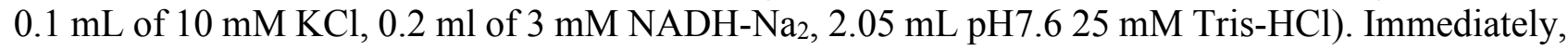
the mixture measured kinetic curve with an interval of $48 \mathrm{~s}$, a total of 8 mins at $340 \mathrm{~nm}^{[12]}$, Consider the reaction solution reducing $1 \mu \mathrm{mol} \mathrm{NADH}-\mathrm{Na} 2$ variation per minute as an enzyme unit.

Stem quality determination. Determination of soluble protein content ${ }^{[8]} .2 \mathrm{~mL}$ PBS buffer was added to $0.25 \mathrm{~g}$ pseudostems in a mortar to homogenate. $12000 \mathrm{r} / \mathrm{min}$ centrifugation $20 \mathrm{mins}$. Putting $50 \mu 1$ supernatant to a new tube make up to $150 \mu 1$ with PBS. Added $2.85 \mathrm{~mL}$ Coomassie blue dye, fully mix well keep stationary state 10 mins. Then measured the absorbance at $595 \mathrm{~nm}$.

Determination of soluble sugar content. $0.5 \mathrm{~g}$ pseudostems were cut and mixed into test tube which injected $10 \mathrm{~mL}$ of distilled water in advance. These tubes were sealed in boiling water for half an hour (extracted twice). The extract was transferred to a centrifuge tube to centrifuge at $10000 \mathrm{r} / \mathrm{min}$ for 10 mins. After that, the supernatant was poured into $25 \mathrm{~mL}$ volumetric flask. Pipet $0.5 \mathrm{~mL}$ solution and then make up to $1.0 \mathrm{~mL}$ with distilled water in a new tube which was added to $1 \mathrm{~mL} \mathrm{5 \%}$ phenol, $5 \mathrm{~mL}$ concentrated sulfuric acid solution in advance. After placed for 20 mins, $470 \mathrm{~nm}$ wavelength colorimetric assay was carried out.

Determination of nitrate content. $3.0 \mathrm{~g}$ pseudostems were chopped and puted into a test tube which $10 \mathrm{~mL}$ distilled water was added to in advance. These tube were sealed in boiling water for half an hour. After cooled to room temperature, the extract with the residue would be transferred to a centrifuge tube to centrifuge at $10000 \mathrm{r} / \mathrm{min} 5 \mathrm{mins}$. Then the supernatant was poured into $25 \mathrm{~mL}$ volumetric flask. $0.1 \mathrm{~mL}$ extracting solution reacted with $0.4 \mathrm{~mL} \mathrm{5 \%}$ salicylic acid solution in a new tube at room temperature for half an hour ${ }^{[6]}$. Then $9.5 \mathrm{ml} 8 \%$ sodium hydroxide solution was added to 
the test tube. Cools it to ambient temperature, $470 \mathrm{~nm}$ wavelength colorimetric assay was carried out $^{[9]}$.

Determination of free amino acid content. $3 \mathrm{~mL} \mathrm{10 \%}$ acetic acid was added to $0.25 \mathrm{~g}$ pseudostems in a mortar to make homogenate. $12000 \mathrm{r} / \mathrm{min}$ centrifugation $20 \mathrm{mins}$. After that, the supernatant was poured into $25 \mathrm{~mL}$ volumetric flask. Mix up $1 \mathrm{~mL}$ extracting solution with $3 \mathrm{~mL} 2 \%$ Ninhydrin in a test tube and add $0.1 \mathrm{~mL} 1 \%$ ascorbic acid solution. These tubewere sealed in boiling water for $15 \mathrm{mins}$. Rapid cooling. The test tube make up to $10 \mathrm{~mL}$ with $60 \%$ ethanol solution ${ }^{[7]} .570 \mathrm{~nm}$ wavelength colorimetric assay was carried out ${ }^{[6]}$.

Determination of Vitamin C content. $4.0 \mathrm{~g}$ pseudostem was added to $5 \mathrm{ml} 0.2 \mathrm{~mol} / \mathrm{L}$ EDTA solution to homogenate in a mortar. It is centrifuged by $5000 \mathrm{r} / \mathrm{min}$ for $10 \mathrm{mins}$. Then the supernatant was transferred to $25 \mathrm{~mL}$ volumetric flask to volume. Adding $1 \mathrm{~mL}$ supernatant to the test tube which inject $0.5 \mathrm{~mL} \mathrm{3 \%}$ metaphosphoric acid, $1 \mathrm{~mL} \mathrm{5 \%}$ phosphoric acid and $2 \mathrm{~mL} \mathrm{5 \%}$ ammonium molybdate. These tube hermetically are heated to $30^{\circ} \mathrm{C}$ for 15 mins. Dilute the solution with distilled water before you measure it. $760 \mathrm{~nm}$ wavelength colorimetric assay was carried out.

Determination of pyruvic acid content ${ }^{[10]} .1 .0 \mathrm{~g}$ pseudostem was added to $6 \mathrm{~mL} 8 \%$ trichloroacetic acid solution in mortar to make homogenate. $10000 \mathrm{r} / \mathrm{min}$ Centrifugation $5 \mathrm{mins}$. the supernatant was transferred to $25 \mathrm{~mL}$ volumetric flask. Take $1 \mathrm{~mL}$ the solution and add $2 \mathrm{~mL} 8 \%$ trichloroacetic acid solution, $1 \mathrm{~mL} 0.1 \%$ 2,4-dinitrophenylhydrazine solution to a new test tube. Then adding $5 \mathrm{ml} 1.5$ $\mathrm{mol} / \mathrm{L} \mathrm{NaOH}$ solution. $520 \mathrm{~nm}$ wavelength colorimetric assay was carried out.

\section{Results and discussion.}

The effects of differen nitrogen levels on nitrate reductase activity of green onions. Nitrate reductase (NR) is an enzyme involved in nitrate assimilation ${ }^{[11]}$. As can be seen from Fig.1, during the whole growth period of Allium fistulosum L, the NR activity of Scallion leaf showed a parabola shape of valley-peak-valley. The peak of NR activity appears at the vigorous growth stage and the lowest appears at harvest stage. Compared with the N-free experimental field, the NR activity of using the full nitrogen level and nitrogen level halved by half experimental field increased by $41.3 \%$ and $79 \%$ at the leaf fast-growing stage respectively. In seeding over-summer, vigorous growth stage, cauloid forming stage, NR activity was strongest under the conditions of the nitrogen level halved.

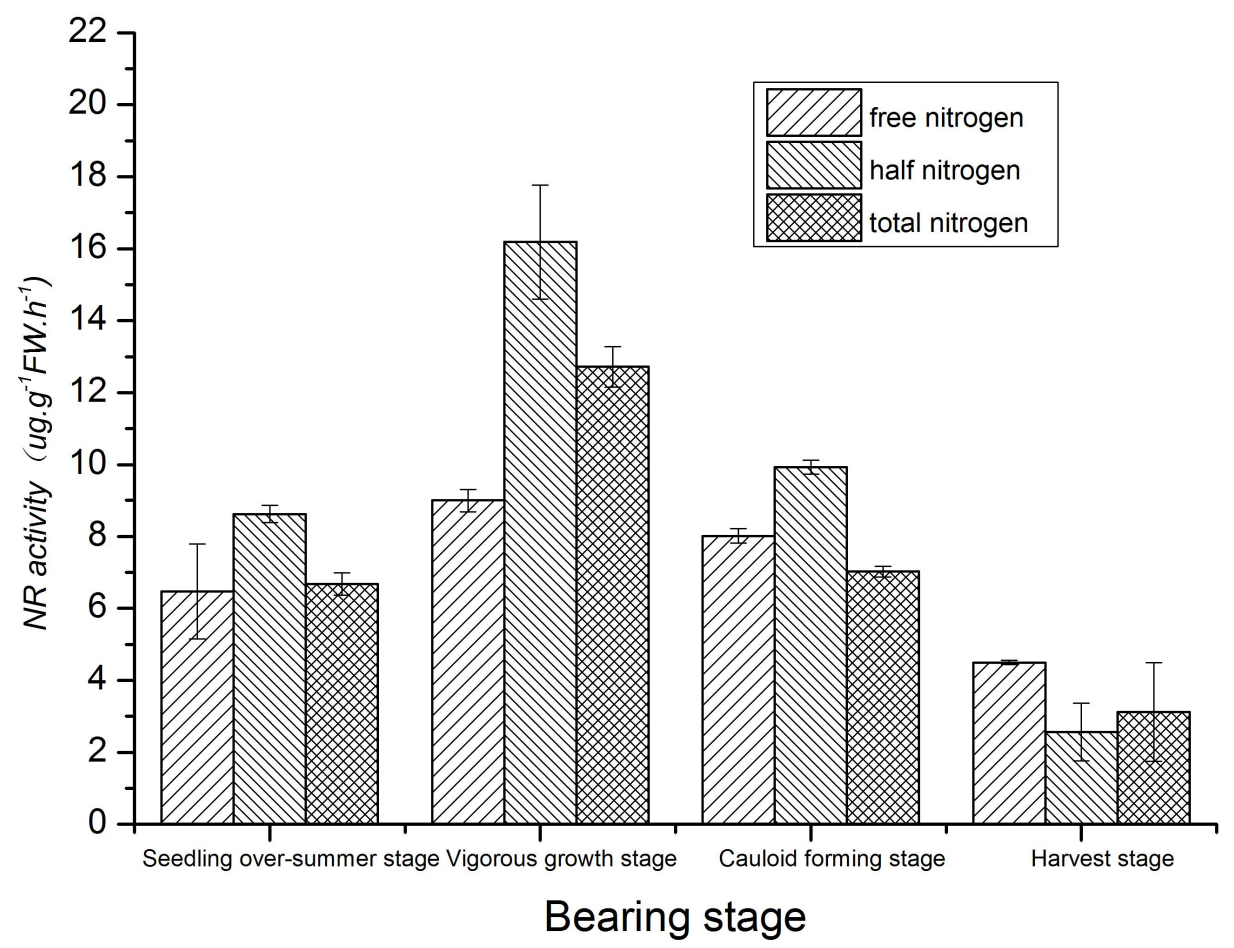

Fig.1 NR activity in leayes of scallion under different nitrogen levels 
The effects of different nitrogen levels on Glutamine Synthetase (GS), Glutamate Synthetase (GOGAT) and Glutamate Dehydrogenase (GDH) activity of Allium fistulosum L.. Glutamine synthetase (GS) can promote the extra ammonium ion combining with glutamate, to prevent the accumulation of ammonium ions caused by poison ${ }^{[12]}$. As can see from the Fig.2, with the growth of Allium fistulosum L., the activity of GS showed a unimodal variation and increased with the increase of nitrogen application rate at vigorous growth stage, the cauloid forming stage and the harvest stage. The GS activity was the lowest at vigorous growth stage and reached the maximum at harvesting stage which was about $6.86 \%-11.08 \%$ higher than that of the nitrogen free condition. The effect of nitrogen on GS activity was not significant during seedling over-summer stage of Allium fistulosum L.. GOGAT plays a key role in the conversion of inorganic nitrogen to organic nitrogen ${ }^{[13]}$. As can see from the Fig.3, during the growth of Allium fistulosum L., the activity of GOGAT showed the trend of valley-peak-valley, and the peak value appeared in the vigorous growth stage. Moreover, the activity of GOGAT applied to nitrogen was significantly higher than that of nitrogen-free condition by $94.9 \%-149.9 \%$. When nitrogen level halved, the activity of GOGAT was the highest which is about $149 \%$ higher than that of nitrogen free condition. GDH plays an initial role in the synthesis of $\mathrm{NH}^{4+}$ and plays a complementary role in the glutamate synthesis cycle ${ }^{[12]}$. The resulting glutamate or glutamine forms a variety of amino acids or amides under the action of aminotransferases, thereby synthesizing the protein. As can see from the Fig.4 during seedling over-summer stage and vigorous growth stage of green onions, the GDH activities were higher than other periods. In particular, the enzyme activity was highest when the nitrogen level is reduced by half. However, the activity of GDH decreased significantly at the cauloid and harvesting stage. The highest activity of GDH appeared in the vigorous growth stage under the conditions of the nitrogen level halved.

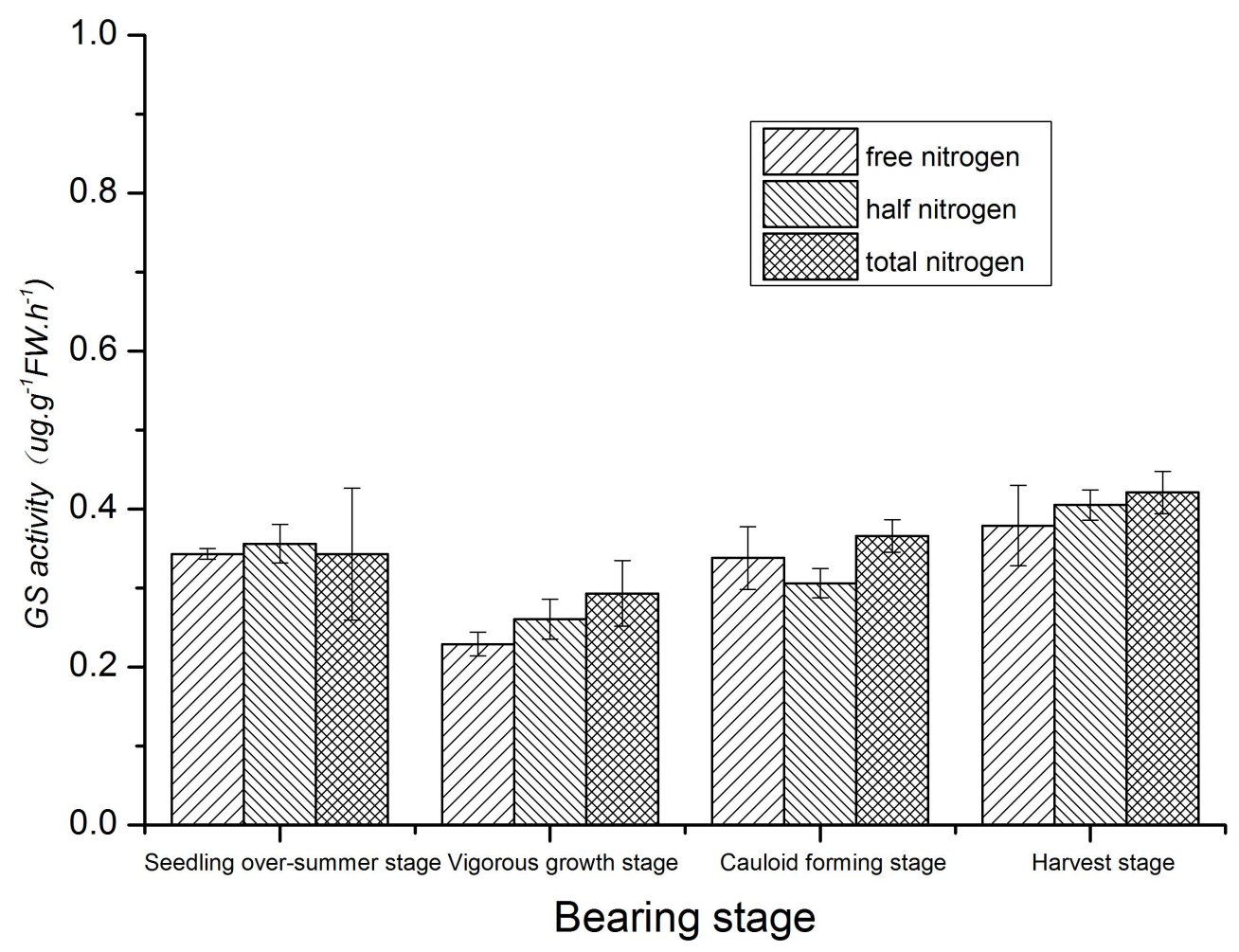

Fig.2 GS activity in leaves of scallion under different nitrogen 


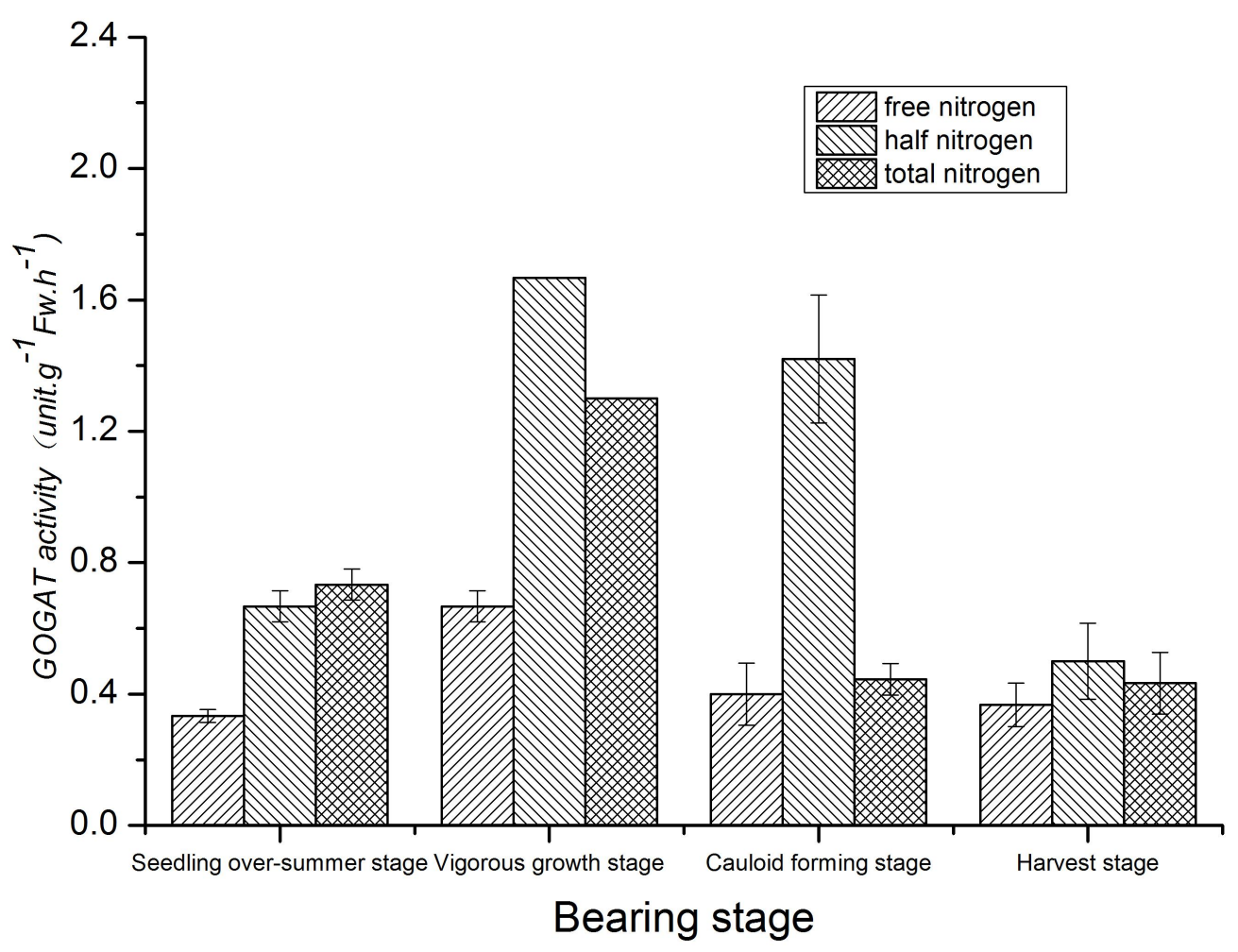

Fig.3 GOGAT activity in leaves of scallion under different nitrogen levels

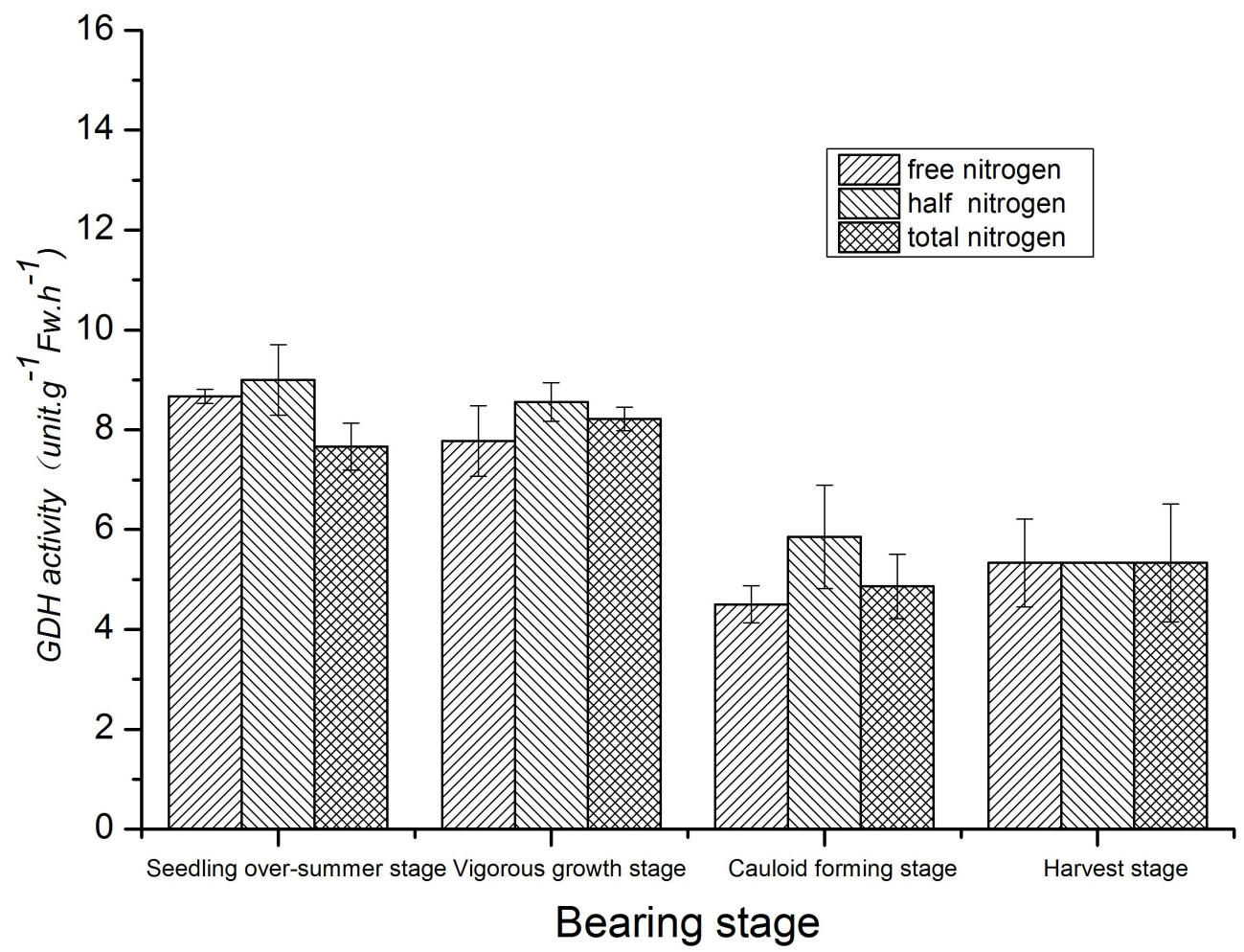

Fig.4 GDH activity in leaves of scallion under different nitrogen levels

The determination of stem quality. As can be drawn from the Fig.5, the contents of pyruvate and free amino acids increased significantly with the increase of nitrogen level and compared with no nitrogen they increased by $123.04 \%$ and $309.11 \%$, respectively. With the increase of nitrogen level amount, the content of soluble sugar, vitamin C, nitric acid Salt showed a trend of firstly that increased and then decreased. It's the largest content in condition of nitrogen level halved. However, the contents of soluble protein was the lowest in nitrogen level halved. 

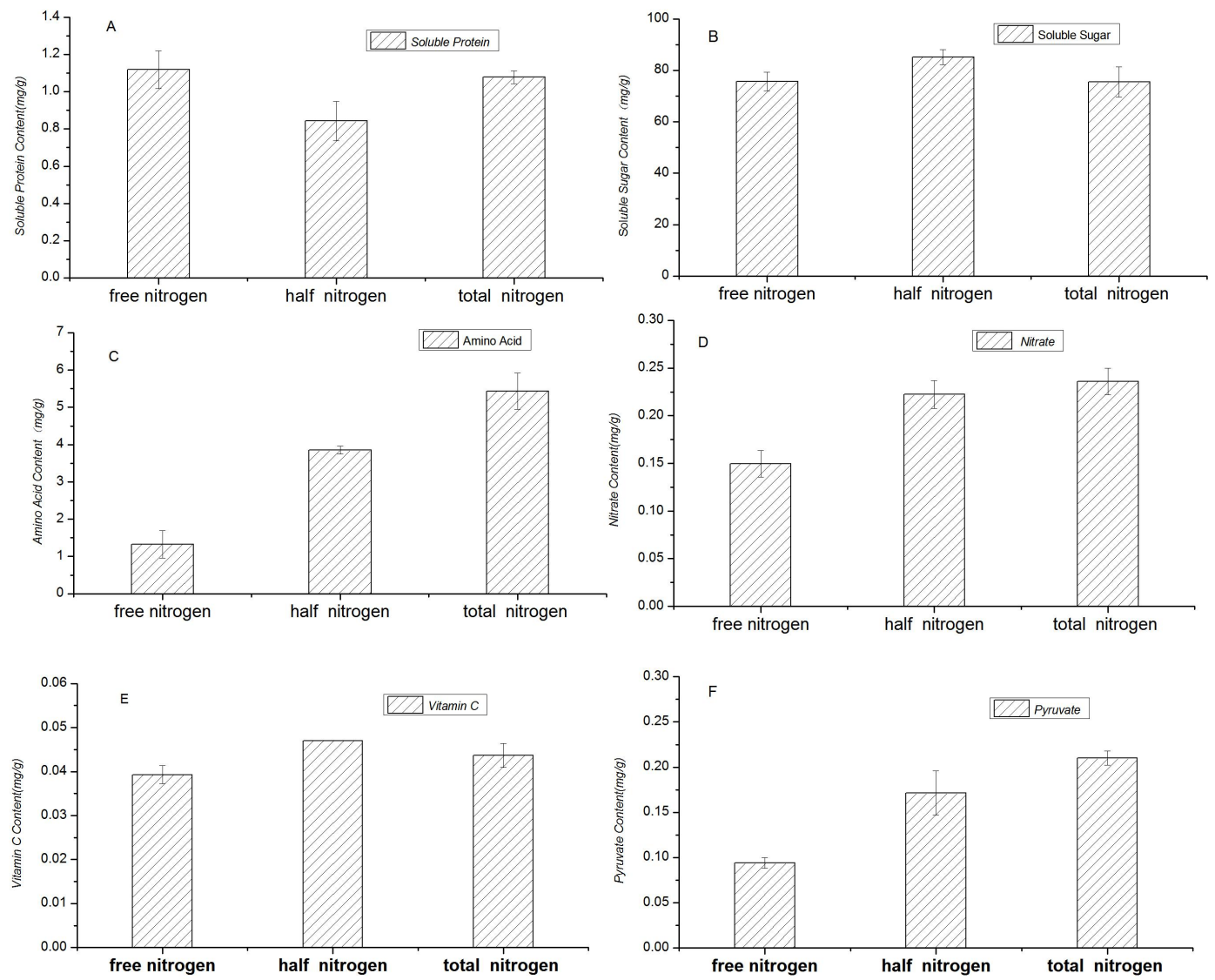

Fig.5 Effect of nitrogen level on metabolite of Allium fistulosum L.

Note: A-Soluble Protein; B-Soluble Sugar; C-Amino Acid; D-Nitrate Content;

E-Vitamin C; F-Pyruvate

\section{Conclusions}

In summary, nitrogen level had a significant effect on the nitrogen metabolism-related enzyme activities, soluble sugar, pyruvate and vitamin C. Appropriately increasing the nitrogen level could increase the output of soluble sugar, vitamin $\mathrm{C}$ and nitrate, but also improved the activity of nitrate reductase, glutamate synthetase,especially. When nitrogen is halved at vigorous growth stage, enzyme activity and yield mentioned above were highest. The activities of glutamine synthetase, pyruvate and free amino acids increased with the amount of the nitrogen applied. During seedling over- summer stage and harvest period of scallion, the enzyme activity was higher. glutamate dehydrogenase activity was the most exuberant in seedling over-summer and vigorous growth stage in Scallion. Therefore, the appropriate amount of nitrogen 1 can increase the yield of scallion, so as not to blindly fertilize fertilizers cause the waste of fertilizer or insufficient fertilization, which can not fully play the potential of the yield increase, and achieve higher output with suitable inputs.

\section{Acknowledgements}

This work was financially supported by National Key R\&D Program of China (No. 2016YFD0200100).

\section{References}

[1] ZHANG Yi,WANG Yun,LIU Can-yu. Effect of calcium level on growth and nitrogen metabolism of Welsh onion[J]. Journal of Plant Nutrition and Fertilizer , 2016, 22(5): 1366-1373. 
[2] Jiang L H, Liu Z H, Chen Q, et al. Study on the effect of nitrogen on green Chinese onion yield and N supplying target value[J]. Plant Nutrition \& Fertilizer Science, 2007.

[3] Cai D, Jianming L I, Fan X, et al. Effect of nitrogen, phosphorus and potassium supplementation on nutrient uptake,yield and quality of tomato in substrate culture[J]. Journal of Northeast Agricultural University, 2017.

[4] Shi J, Li W Q, Hou L L, et al. Effects of N, P, K combined application on the yield, nutrition absorption and utilization characteristics of Allium fistulosum[J]. Plant Physiology Journal, 2015, 51(6): $847-852$.

[5] Kong L J, Xu K, Wang L, et al. Influence of nitrogen and sulfur interaction on growth and quality of Chinese spring onion[J]. Journal of Plant Nutrition and Fertilizer, 2013, 19(5): 1272-1278.

[6] Zhao S J, Liu H S, Dong X C. Techniques of plant physiological experiment[M]. Beijing: China Agricultural Science and Technology Press, 2002. 40 - 99.

[7] Cren M, Hirel B. Glutamine synthetase in higher plant: regulation of gene and protein expression from the organ to the cell[J]. Plant and Cell Physiology, 1999, 40(12): 1187 - 1193.

[8] Northwestern Agricultural University. Guide of biochemistry experiment[M]. Xi' an: Shanxi Science and Technology Press, 1986. 110 - 111.

[9] Krom M D. Spectrophotometric determination of ammonia: a study of a modified Berthelot reaction using salicylate and dichloroisocyanurate[J]. Analyst, 1980, 105(1249): 305 - 316.

[10] Liu L, Liu S, Xu L, et al. Studies on the changes of nitrogen metabolism and peroxidase activity in onions during different photoperiod and vernalization[J]. Acta Agriculturae Boreali-occidentalis Sinica, 2005.

[11] Wang L P, Sun J, Guo S R, et al. Effects of graft with pumpkin rootstock on nitrogen metabolism and protein expression in the cucumber seedlings under iso-osmotic $\mathrm{Ca}(\mathrm{NO} 3)_{2}$ or $\mathrm{NaCl}$ stress[J].Plant Nutrition and Fertilizer Science, 2012, 18(3): 689 - 698.

[12] Miflin B J, Habash D Z. The role of glutamine synthetase and glutamate dehydrogenase in nitrogen assimilation and possibilities for improvement in the nitrogen utilization of crops[J]. Journal of Experimental Botany, 2002, 53(370): 979 - 987.

[13] Lam H M, Coschigano K T, Oliveira I C. The molecular-genetics of nitrogen assimilation into amino acids in higher plants[J]. Annual Review of Plant Physiology and Plant Molecular Biology, 1996, 47(1): 569 - 593.

[14] Zolfaghari B, Yazdiniapour Z, Sadeghi M, et al. Furostanol Saponins from the Bulbs of Welsh Onion, Allium fistulosum L[J]. Planta Medica, 2016, 82(18):1584-1590.

[15] Li H, Liu S Q, Liu Z L, et al. Effects of calcium on physiological characteristics and main mineral elements absorption of garlic[J]. Scientia Agricultura Sinica, 2013, 46(17): 3626-3634.

[16] Sun X D, Yu X H, Zhou S M, et al. De novo assembly and characterization of the Welsh onion (Allium fistulosum L.) transcriptome using Illumina technology[J]. Molecular Genetics \& Genomics, 2016, 291(2):647-659. 